\title{
Promising upshot of silver nanoparticles primed from Gracilaria crassa against bacterial pathogens
}

\author{
V Lavakumar ${ }^{1}$, K Masilamani $^{2}$, V Ravichandiran ${ }^{3}$, N Venkateshan $^{4}$, D V R Saigopal ${ }^{5}$, C K Ashok Kumar $^{1}$ \\ and C Sowmya ${ }^{6^{*}}$
}

\begin{abstract}
Background: The study on newer antimicrobial agent from metal based nano materials has augmented in recent years for the management of multidrug resistance microorganisms. In our present investigation, we synthesized silver nanoparticles (AgNP's) from red algae, Gracilaria crassa as beginning material which effectively condensed the silver ions to silver nanoparticles with less price tag and no risk.

Methods: Silver nanoparticles were prepared by simple reaction of $1 \mathrm{mM} \mathrm{AgNO}_{3}$ with $\mathrm{G}$. crassa extracts at room temperature. The fabricated AgNP's were subjected for characterization and screened against various microorganisms for antibacterial activity.

Results: UV-Vis spectroscopy (200-800 nm), XRD, FESEM and EDAX, were performed for AgNP's. UV-Vis spectroscopy demonstrated the absorption edge at $443 \mathrm{~nm}$ and EDAX pattern is purely due to the particle size and face centered cubic (fcc) symmetry of nanoparticles. Average size lays at $122.7 \mathrm{~nm}$ and zeta potential was found to be $-34.9 \mathrm{mV}$. The antibacterial outcome of synthesized AgNP's (at the dose of 20 and $40 \mu \mathrm{g} / \mathrm{ml}$ ) was evaluated against Escherichia coli, Proteus mirabilis, Bacillus subtilis and Pseudomonas aeruginosa. The mechanism of synthesized AgNP's bactericidal bustle is discussed in terms of interaction with the cell membrane of bacteria. The activity was found to be sky-scraping in a dose dependent manner.

Conclusion: Thus, environmental friendly, cost effective, non hazardous stable nanoparticles were prepared by green synthesis using red algae, G. crassa. Synthesized G. crassa AgNP's were in acceptable size and shape. Further, it elicits better bactericidal activity against microorganism. This will assure the out put of superior antibacterial formulation for near future.
\end{abstract}

Keywords: Green synthesis, Red algae, Gracilaria crassa, Silver nanoparticles, Antibacterial activity

\section{Background}

From ancient, handling of microbial infection is an exigent task for microbiologists. Countless drugs have been found to be successful, unfortunately, it leads to mount of drug resistance against particular pathogens with an outlook of stern issues in concern with public wellbeing [1]. Technical community is animatedly trying to expand

\footnotetext{
*Correspondence: drsowmyariper@gmail.com

${ }^{6}$ Department of Pharmaceutics, Raghavendra Institute of Pharmaceutical

Education and Research, Anantapuram 515721, AP, India

Full list of author information is available at the end of the article
}

groundbreaking concepts in drug delivery by challenging the new microbial agent with superior mode of action by its effectual target on the cell membrane or neither on intracellular targets $[2,3]$. In 21 st century, nanotechnology has become inevitable, not because of only claim and also by the way of synthesis. Two way synthesis like physical and chemical methods have several sizeable challenges like technically protracted, expensive and ecological hazardous defects [4]. The current art of exploration in research is heading towards green synthesis of high-yield, squat in cost, non-hazardous and eco-friendly metallic nanoparticles by plants and microorganisms $[5$, 
6]. Due to hefty surface area, high reactivity and surface plasmon resonance, these nanoparticles were tailored for definite application by scheming into unambiguous size, shape and morphology leading to exhibit its broad spectrum of activity against multi drug resistance microorganisms [7-10]. A quest for an environmentally sustainable synthesis process has led to a few biomimetic approaches like applying natal principles in the formation of nanoparticles. Among several, bioreduction is the prime and widely practiced functional method in synthesizing the nano materials $[11,12]$. Noble metal nanoparticles such as silver, gold, which are geared up by plant extracts, algae, bacteria and fungi are broadly applied in drug delivery systems [13], electronics [14, 15], biosensors [16], cancer therapeutics and antimicrobial agents [17-19]. For three decades, exploration of marine algae has been far above the ground for the search of new and effective natural origin medicines, because it posses elevated quantity of concealed bioactive essence. Several of such compounds, including carbohydrates, alkaloids, steroids, phenols, saponins and flavonoids, etc. [20-22]. These multifaceted compounds exhibit a wide range of industrial and biotechnological applications [23]. An extent, these bio-molecules play decisive role in reduction of metal ions and generate the stable eco friendly nanoparticles. Further, AgNP's fetches superior antibacterial activity by interacting with thiol clusters present in bacterial cell by cliping its replication. Literature strappingly supports that these $\mathrm{Ag}^{+}$ions unyoke the respiratory chains and collapse the proton motive forces across the cytoplasmic membrane of bacteria [24]. Gracilaria crassa (G. crassa), a well-known red algae, having potential secondary metabolites [25]. In harmony to the above information, the present study was intended to prepare and typify silver nanoparticles from G. crassa, further to explore its antimicrobial activities against highly resistance microbial inhabitants.

\section{Methods \\ Materials}

Silver nitrate $\left(\mathrm{AgNO}_{3}\right.$; Mol. Wt: 169.87; Prod. No: 27462) of analytical grade (AR) was purchased from Fisher scientific, Mumbai, India. The nutrient agar medium was purchased from Hi Media (Mumbai, India). All other chemicals used were analytical grade. Microorganisms such as Escherichia coli (MTCC 443), Proteus mirabilis (MTCC 442), Bacillus subtilis (MTCC 441) and Pseudomonas aeruginosa (MTCC 424) were obtained from Microbial Type Culture and Collection, Pune, India.

\section{Seaweed collection and extraction}

Gracilaria crassa was collected along the coast of Mandapam $\left(9^{\circ} 16^{\prime} 58.9^{\prime \prime} \mathrm{N} \quad 79^{\circ} 18^{\prime} 53.6^{\prime \prime} \mathrm{E}\right), \quad$ Rameswaram,
Tamilnadu, India. The freshly collected algal material was rinsed with seawater followed by deionized water to get rid of extra impurities. The samples were kept in shade for 15 days drying. The algal material was ground to powder and uphold stockpile by placing at $-4^{\circ} \mathrm{C}$ for further studies. The G. crassa extract was prepared in a conical flask by taking $2.5 \mathrm{~g}$ in $100 \mathrm{~mL}$ of deionized water. It was heated for $45 \mathrm{~min}$ at $50^{\circ} \mathrm{C}$ and positioned in an orbital shaker for $24 \mathrm{~h}$ in order to conquer the maximum extraction of compounds. The Extracts were filtered through whatman No. 1 filter paper and stored in refrigerator for further studies [26].

\section{Synthesis of silver nanoparticles}

AgNP's were synthesized by adopting the method proposed by Sathishkumar et al. with simple modification [27]. $5 \mathrm{ml}$ of algal extract was added in to $95 \mathrm{ml}$ of $1 \mathrm{mM}$ aqueous silver nitrate solution, in $250 \mathrm{ml}$ conical flasks and kept at $30^{\circ} \mathrm{C}$ in a shaker for overnight to facilitate absolute reduction. The samples were monitored periodically for its color intensity to confirm the formation of AgNP's.

\section{Characterization of silver nanoparticles UV-Vis spectral analysis}

The reduction in pure silver ions was recorded by measuring the UV-Vis spectrum of the synthesized AgNP's of G. crassa at room temperature with a Perkin Elmer Lambda $25 \mathrm{UV}-\mathrm{Vis}$ spectrometer at the wavelength of 200-800 nm [28].

\section{Particle size and zeta potential studies}

Particle size and zeta potential experiments for G. crassa AgNP's were carried out by using a HORIBA Instruments (Singapore) Pvt Ltd, Singapore.

\section{Powder x-ray diffraction (XRD) analysis}

The silver nanoparticles were alienated by repeated centrifugation at 12,000 rpm for $10 \mathrm{~min}$ followed by redispersion of AgNP's into deionized water for three times. The supernatant was transferred in microwave for drying. X-ray diffraction (XRD) measurement of the AgNP's was carried out using Rigaku smart lab instrument (Japan), function at voltage of $40 \mathrm{kV}, 30 \mathrm{~mA}$ current with $\mathrm{Cu} \mathrm{K} \alpha 1$ radiations.

\section{FESEM-EDAX studies}

After careful UV-Vis spectroscopical analysis of synthesized nanoparticles, diameter of nanoparticles were further confirmed by Field emission scanning electron microscopy-energy dispersive X-ray analysis (FESEM-EDAX) by using SUPRA 55-CARL ZEISS, Germany. 


\section{Antibacterial assay}

The antibacterial evaluation of AgNP's was conceded by using different experimental pathogens like Escherichia coli (MTCC 443), Proteus mirabilis (MTCC 442), Bacillus subtilis (MTCC 441) and Pseudomonas aeruginosa (MTCC 424) maintained by department of Pharmaceutical Biotechnology, SVCP, Tirupati, India. Prior to experimentation, untainted cultures was subcultured into nutrient media. Nutrient agar plates were prepared, seeded and pierced with 20 and $40 \mu \mathrm{g} / \mathrm{ml}$ of AgNP's. Streptomycin sulphate $(20 \mu \mathrm{g} / \mathrm{ml})$ was used as standard [29].

\section{Results and discussion}

\section{UV-Vis spectral analysis}

The formation of AgNP's was defined by color transformation [30] from pale yellow to dark brown (Fig. 1). The color change is due to the excitation of the surface plasmon resonance (SPR) (Fig. 2) which elicits $\lambda$ max of $443 \mathrm{~nm}$.

\section{Particle size and zeta potential}

Particle size determination of synthesized AgNP's was revealed underneath by intensity. Laser diffractions exposed by obtained AgNP's were in polydisperse concoction with average size of $122.7 \mathrm{~nm}$ (Fig. 3). The zeta potential endows stability of nanoparticles and surface charge. The zeta potential was found to be $-34.9 \mathrm{mV}$. Earlier reports strongly supports, when the zeta potential value positions between -30 and $-50 \mathrm{mV}$, it specifies good stability of nano particles [31]. The high negative value (Fig. 4) substantiates the repulsion between the particles and thereby increases the stability of the AgNP's.

\section{X-ray diffraction (XRD) analysis}

The XRD pattern of powder sample of G. crassa AgNP's exhibited peaks at $38^{\circ}, 44^{\circ}, 64^{\circ}$ and $77^{\circ}$. Four Bragg's

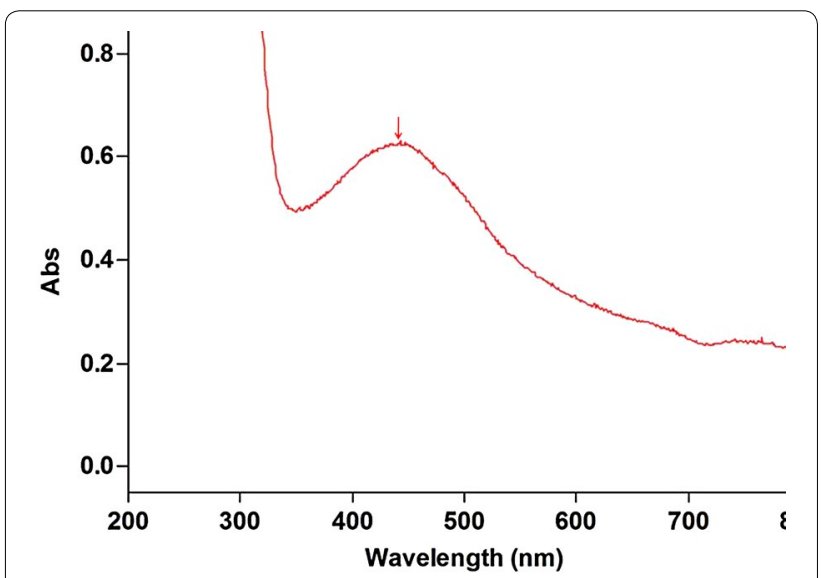

Fig. 2 UV-Vis absorption maxima of silver nanoparticles. The data is based on the presence of absorbance peak of AgNP's solution at the wavelength range of $400-450 \mathrm{~nm}$. The absorption maxima were found to be $434 \mathrm{~nm}$. reflections corresponding to (111), (200), (220) and (311) planes of the fcc crystal structures of metallic silver (JCPDS No. 89-3722) are interpreted from the XRD (Fig. 5). The orientation (111) is more predominant since it shows high intense. Broadening of the diffraction crest disclose the formation of pure crystalline silver [32].

\section{FESEM and energy dispersive X-ray analysis}

Field emission scanning electron microscopy investigation was further confirmed the size of silver nanoparticles synthesized from G. crassa. The size (diameter) of the nanoparticles ranges between 60 and $200 \mathrm{~nm}$ and the shapes were spherical and some are irregular (Fig. 6). The outcome of FESEM reports were overlapped with earlier reports [33, 34]. The energy dispersive X-ray analysis (EDAX) depicts strong indication in the silver region, which authenticate formation of silver nanoparticles

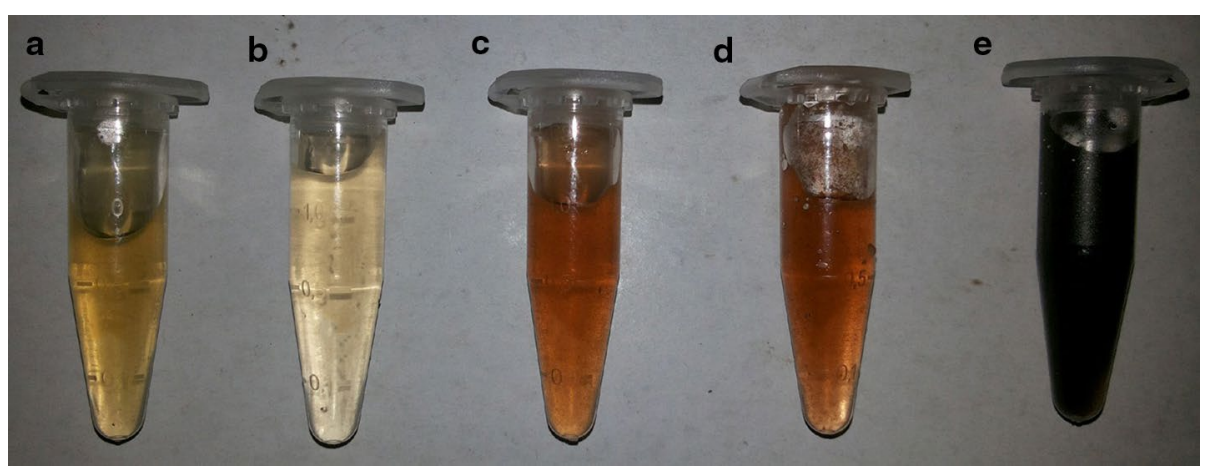

Fig. 1 Formation of silver nanoparticles by green synthesis. AgNP's were formed by the reduction of silver ions by Gracilaria crassa. This figure illustrates the various stages of formation of AgNP's; a pure algal extracts (pale yellow); $\mathbf{b}$ at 0 min, on immediate addition of 1 mM solution of Silver nitrate (no reaction); c after 15 min (slight reduction); d after 30 min (moderate reduction); e after 12 h of addition of 1 mM solution of Silver nitrate (Complete reduction). 


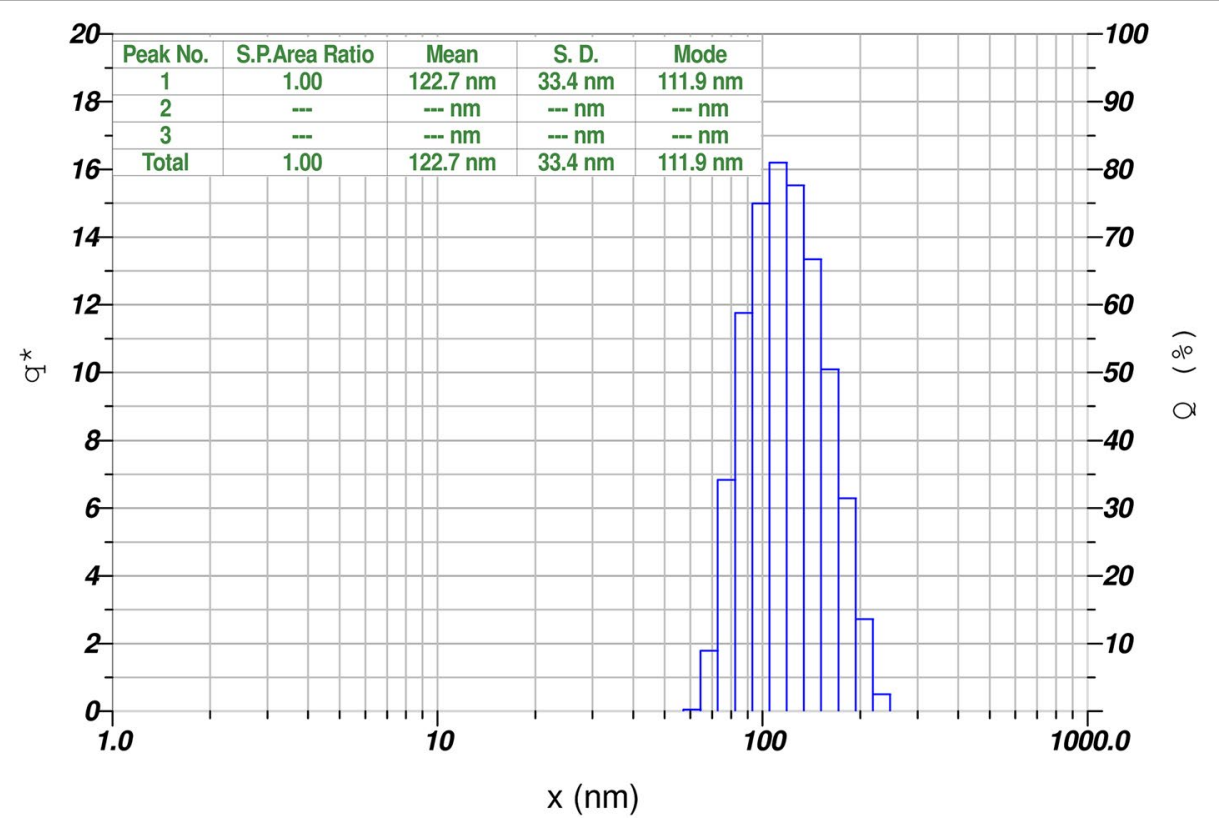

Fig. 3 Particles size distribution of AgNP's prepared from G. crassa extracts. Average particle size of synthesized AgNP's ranges from 60 to 200 nm

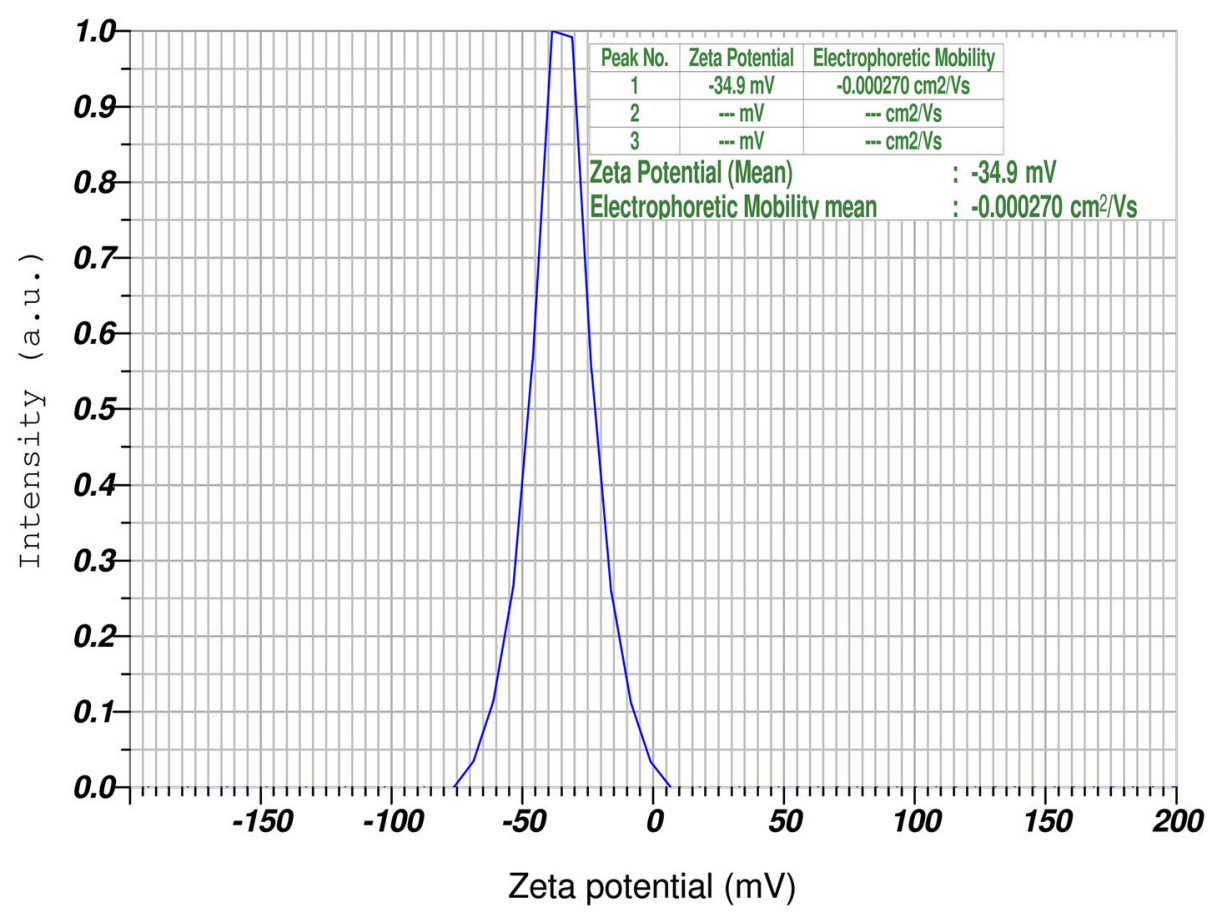

Fig. 4 Zeta potential illustration of AgNP's. Zeta potential distribution of synthesized AgNP's prepared from G. crassa extracts. 


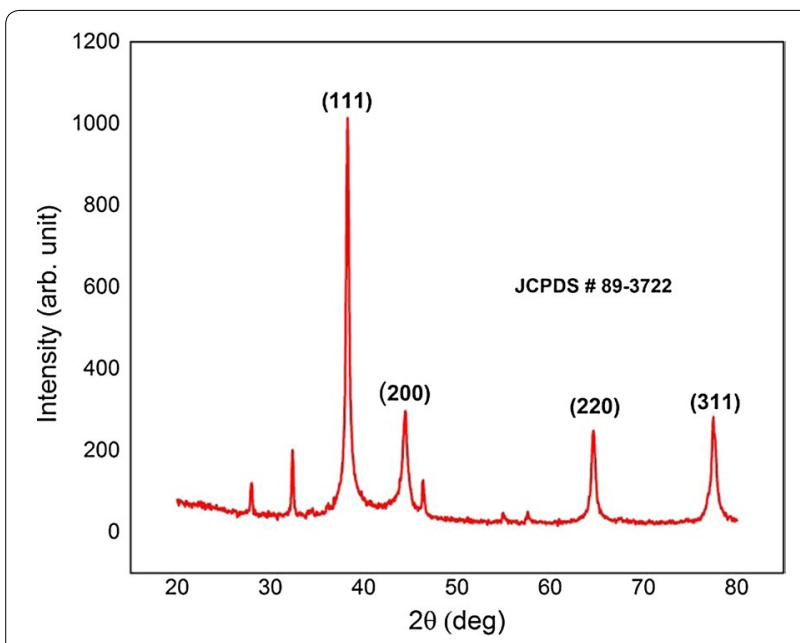

Fig. 5 X-ray diffraction analysis of bio synthesized silver nanoparticles using marine red algae extracts of $G$. crassa corresponds four Bragg's reflections planes of the metallic silver nanoparticles.

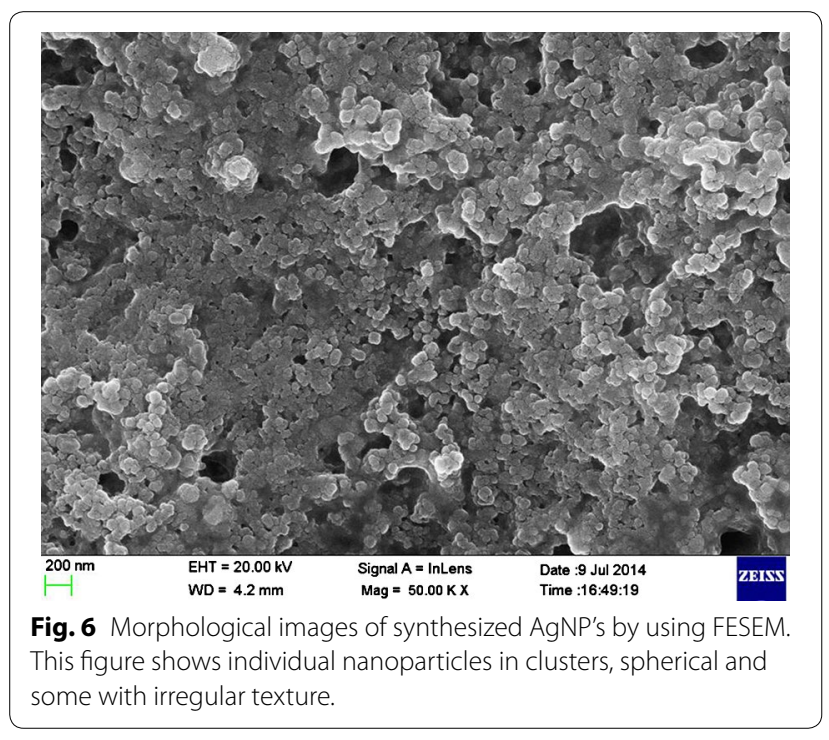

(Fig. 7). The optical absorption peak at $3 \mathrm{kV}$, which attributed to metallic silver nanocrystallites owing to surface plasmon resonance $[35,36]$.

\section{Antibacterial assay}

Antibacterial activity by agar well diffusion technique was recorded after $24 \mathrm{~h}$ incubation of culture plates.

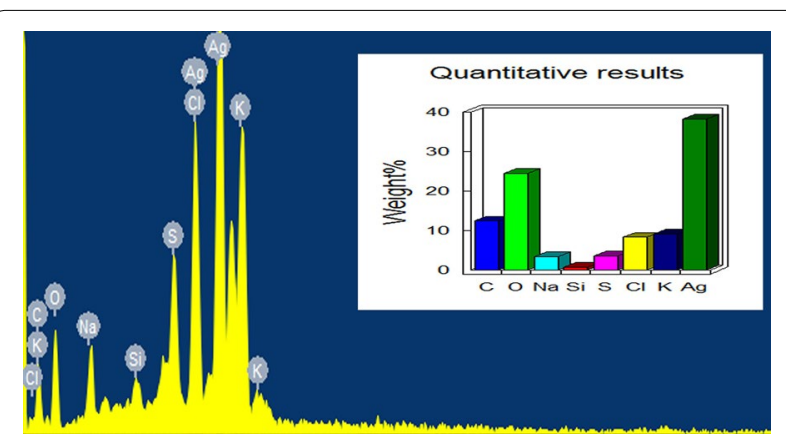

Fig. 7 Energy dispersive X-ray analysis of silver nanoparticles. EDAX profile of AgNP's shows higher percentage of silver signal.

The AgNP's demonstrate excellent antibacterial activity against all tested microorganisms (Fig. 8). AgNP's showed high spectrum of activity against $E$. coli and $P$. mirabilis at the concentrations of 20 and $40 \mu \mathrm{g} / \mathrm{ml}$ when compared with standard (Fig. 9). The significant zone of inhibition was exerted due to effect of AgNP's on biochemical process of the bacterial cell by interacting thiol and amino groups of proteins and nucleic acids of cell wall [37-39]. Further, this could lead to interaction between nanoparticles and microorganism which results in triggering the discharge of highly reactive oxygen species (ROS), mostly hydroxyl radicals and singlet oxygen [40-42]. This augments the deposition of nanoparticles on the bacterial cell surface results large accumulation of silver nanoparticles causing disruption of cellular functions.

\section{Conclusion}

In summary, the bio-reduction of aqueous silver ions to silver nanoparticles (AgNP's) was successfully done using marine red algae, G. crassa in trouble-free, economy and ecofriendly manner. The average size of silver nanoparticles was found to be $122.7 \mathrm{~nm}$ with high stability of $-34.9 \mathrm{mV}$. Further characterization by UV-Vis spectroscopy, FESEM, EDAX confirm formation nanoparticles which are virtually spherical in shape. XRD divulges fcc structural confirmation. The proved antibacterial potential will lend a hand to develop a powerful antibacterial formulation in near future as biomedical remedies. Hence, authors robustly propose this green synthesis of nanoparticles can be extended to the wide range of applications. 

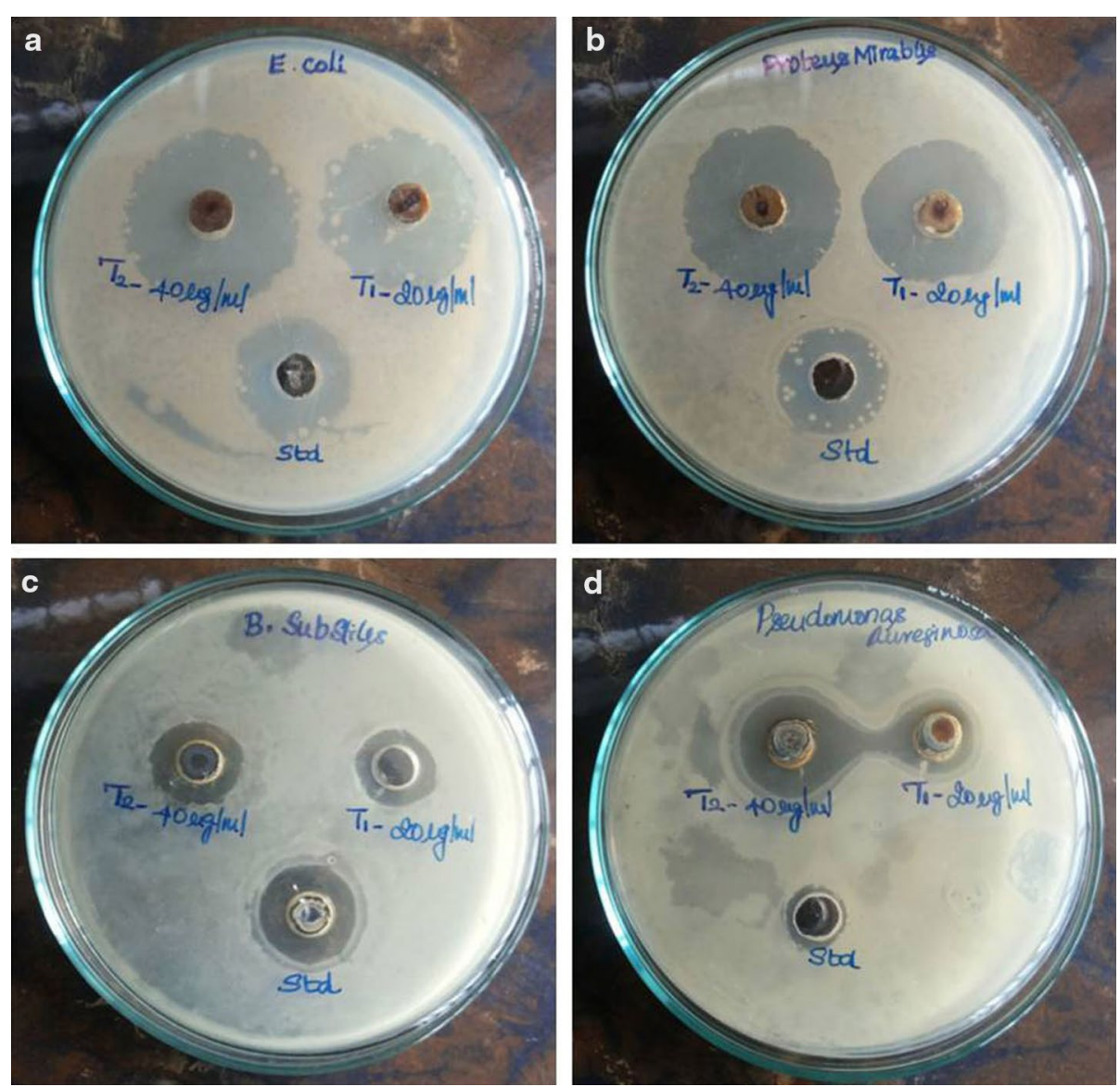

Fig. 8 Antibacterial activity of AgNP's. Zone of inhibition of silver nanoparticles against a Escherichia coli, $\mathbf{b}$ Proteus mirabilis, c Bacillus subtilis, $\mathbf{d}$ Pseudomonas aeruginosa; [T $1-\left(20 \mu \mathrm{g} / \mathrm{ml}\right.$ of AgNP's) and $\mathrm{T}_{2}(40 \mu \mathrm{g} / \mathrm{ml}$ of AgNP's); Standard (Std-Streptomycin sulphate $\left.20 \mu \mathrm{g} / \mathrm{ml})\right]$.

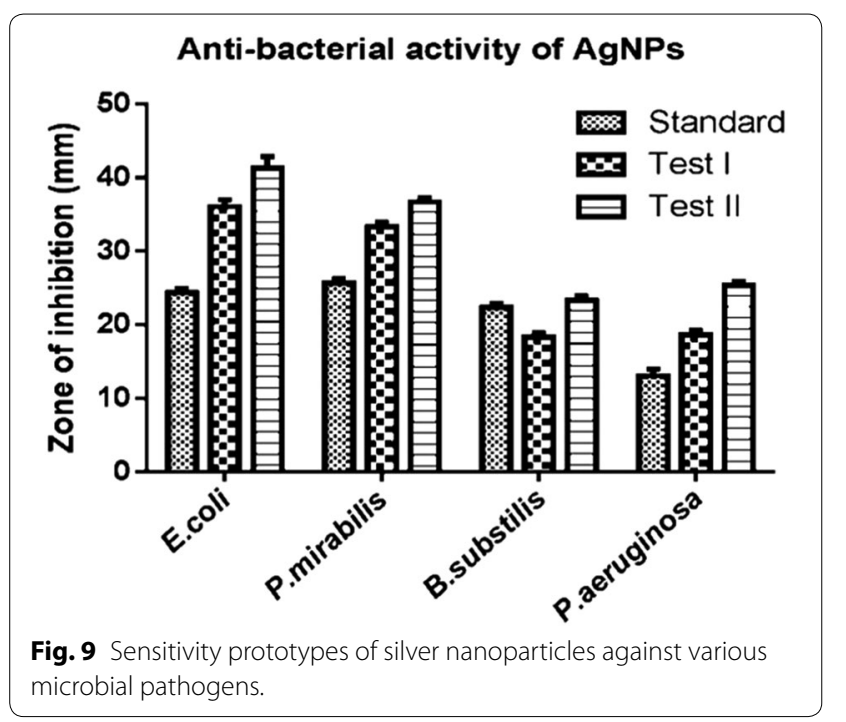

\section{Abbreviations}

AgNP's: silver nanoparticles; FESEM: field emission scanning electron microscopy; EDAX: energy dispersive analysis of X-rays; XRD: X-ray diffraction; Fcc: face centered cubic; Cu: copper; mV: millivolts; SPR: surface plasmon resonance; $\mathrm{kV}$ : kilovolts; $\mathrm{mM}$ : millimolar; nm: nanometer; ROS: reactive oxygen species; MTCC: microbial type culture and collection.

\section{Author's contributions}

LKV and SC are designed, performed and wrote the manuscript. MK contributed for instrumentation. RV \& VN helped in interpretation of FESEM and XRD. AK \& SG were helped in screening antimicrobial activity. All authors read and approved the final manuscript.

\section{Author details}

1 Department of Pharmaceutical Biotechnology, Sree Vidhyanikethan College of Pharmacy, A.Rangampet, Tirupati 517102, AP, India. ${ }^{2}$ Faculty of Technology, University Malaysia Pahang, Lebuhraya Tun Razak, Gambang, 26300 Kuantan, Pahang Darul Makmur, Malaysia. ${ }^{3}$ National Institute of Pharmaceutical Education and Research, Kolkata 700032, WB, India. ${ }^{4}$ Department of Pharmaceutical Chemistry, Sankarlingam Bhuvaneswari College of Pharmacy, Sivakasi 626130, TN, India. ${ }^{5}$ Department of Virology, S.V. University, Tirupati 517502, AP, India. ${ }^{6}$ Department of Pharmaceutics, Raghavendra Institute of Pharmaceutical Education and Research, Anantapuram 515721, AP, India. 


\section{Acknowledgements}

The authors are grateful to T.N.K.V. Prasad, Institute of Frontier Technology, Regional Agricultural Research Station, Acharya N.G. Ranga Agricultural University, Tirupati for helping us to carry out particle size analysis. The authors also thankful to Center for nanotechnology, Sathyabhama University, Chennai for carrying out FESEM and XRD studies. The authors extended thanks to Sree Vidyanikethan College of Pharmacy, A.Rangampet, Tirupathi for providing facilities to carry out this work.

\section{Compliance with ethical guidelines}

\section{Competing interests}

The authors declare that they have no competing interests.

Received: 6 March 2015 Accepted: 16 July 2015

Published online: 07 August 2015

\section{References}

1. Rezai K, Weinstein RA (2010) Antimicrobial resistance-beyond the breakpoint: reducing antimicrobial-resistant infections in health care setting: what works. Issues Infect Dis 6:89-101

2. Sosa IO, Noguez C, Barrera RG (2003) Optical properties of metal nanoparticles with arbitrary shapes. J Phys Chem B 107:6269-6275

3. Xie J, Lee JY, Wang DIC, Ting YP (2007) Silver nanoplates: from biological to biomimetic synthesis. ACS Nano 1:429-439

4. Ahmad N, Sharma S, Md Alam K, Singh VN, Shamsi SF, Mehta BR et al (2010) Rapid synthesis of silver nanoparticles using dried medicinal plant of basil. Colloids Surf B Biointerfaces 81:81-86

5. Mandal D, Bolander ME, Mukhopadhyay D, Sarkar G, Mukherjee P (2006) The use of microorganisms for the formation of metal nanoparticles and their application. Appl Microbiol Biotechnol 69:485-492

6. Gardea-Torresdey JL, Tiemann KJ, Gomez E, Dokken K, Tehuacanero S, Jose-Yacaman M (1999) Gold nanoparticles obtained by bio -precipitation from gold (III) solutions. J Nanopart Res 1:397-404

7. Krutyakov YA, Kudrynskiy AA, Olenin AY, Lisichkin GV (2008) Synthesis and properties of silver nanoparticles: advances and prospects. Russ Chem Rev 77:233-257

8. Alivisatos AP (1996) Semiconductor clusters, nanocrystals, and quantum dots. Science 271:933-937

9. Mubarakali D, Thajuddin N, Jeganathan K, Gunasekharan M (2011) Plant extract mediated synthesis of silver and gold nanoparticles and its antibacterial activity against clinically isolated pathogens. Colloids Surf B Biointerfaces 85:360-365

10. Kelly KL, Coronado E, Zhaoand LI, Schatz GC (2003) The optical properties of metal nanoparticles: the influence of size, shape, and dielectric environment. J Phys Chem B 107:668-677

11. Song JY, Kim BS (2009) Rapid biological synthesis of silver nanoparticles using plant leaf extracts. Bioprocess Biosyst Eng 32:79-84

12. Faramarzi MA, Sadighi A (2013) Insights into biogenic and chemical production of inorganic nanomaterials and nanostructures. Adv Colloids Interface Sci 189-190:1-20

13. Perugini P, Si Simeon, Scalia S, Genta I, Modena T (2002) Effect of nanoparticle encapsulation on the photostability of the sunscreen agent 2-ethylhexyl-p-methoxycinnamate. Int J Pharm 246:37-45

14. Asharani PV, Lian Wu Yi, Gong Z, Valiyaveettil S (2008) Toxicity of silver nanoparticles in zebrafish models. Nanotechnology 19:255102

15. Jin S, Ye K (2007) Nanoparticle-mediated drug delivery and gene therapy. Biotechnol Prog 23:32-41

16. Prow T, Grebe R, Merges C, Smith JN, McLeod DS, Leary JF et al (2006) Nanoparticle tethered antioxidant response element as a biosensor for oxygen induced toxicity in retinal endothelial cells. Mol Vision 12:616-625

17. Salata OV (2004) Applications of nanoparticles in biology and medicine. J Nanobiotechnol 2:3

18. Husseiny MI, El-Aziz MA, Badr Y, Mahmoud MA (2007) Biosynthesis of gold nanoparticles using Pseudomonas aeruginosa. Spectrochim Acta A Mol Biomol Spectrosc 67:1003-1006
19. Gangadharan D, Harshvardan K, Gnanasekar G, Dixit D, Popat KM, Anand PS (2010) Polymeric microspheres containing silver nanoparticles as a bactericidal agent for water disinfection. J Water Res 44:5481-5487

20. Suriya J, Bharathi Raja S, Sekar V, Rajasekaran R (2012) Biosynthesis of silver nanoparticles and its antibacterial activity using seaweed Urospora sp. Afr J Biotechnol 11:12192-12198

21. Kumar P, Senthamilselvi S, Lakshmiprabha A, Premkumar K, Ganeshkumar RS, Govindaraju M (2012) Synthesis of silver nanoparticles from Sargassum tenerrimum and screening phytochemicals for its antibacterial activity. Nano Biomed Eng 4:12-16

22. Thangaraju N, Venkatalakshmi RP, Chinnasamy A, Kannaiyan P (2012) Synthesis of silver nanoparticles and the antibacterial and anticancer activities of the crude extract of Sargassum polycystum C. Agardh Nano Biomed Eng 4:89-94

23. Holt KB, Bard AJ (2005) Interaction of silver (I) ions with the respiratory chain of Escherichia coli: an electrochemical and scanning electrochemical microscopy study of the antimicrobial mechanism of micromolar $\mathrm{Ag}+$. Biochem 44:13214-13223

24. Renn D (1997) Biotechnology and the red seaweed polysaccharide industry: status, needs and prospects. Trends Biotechnol 15:9-14

25. De almeida CLF, Falcao DS, Lima DM, Gedson R, Montenegro DA, Lira NS et al (2011) Bioactivities from marine algae of the genus gracilaria. Int J Mol Sci 12:4550-4573

26. Das J, Das MP, Velusamy P (2014) Sesbania grandiflora leaf extract mediated green synthesis of antibacterial silver nanoaprticles against selected human pathogens. Spectrochim Acta A Mol Biomol Spectrosc 104:265-270

27. Sathishkumar G, Gobinath C, Karpagam K, Hemamalini V, Premkumar K, Sivaramakrishnan S (2012) Phyto-synthesis of silver nanoscale particles using Morinda citrifolia L. and its inhibitory activity against human pathogens. Colloids Surf B Biointerface 15:235-240

28. Mallikarjuna K, Narasimha G, Dillip GR, Praveen B, Shreedhar B, Sree lakshmi C et al (2011) Green synthesis of silver nanoparticles using Ocimum leaf extract and their characterization. Dig J Nanometer Bios 6:81-186

29. Shahverdi AR, Fakhimi A, Shahverdi HR, Minaian S (2007) Synthesis and effect of silver nanoparticles on the anti bacterial activity of different antibiotics against Staphylococcus aureus and Escherichia coli. Nanomed 3:168-171

30. Sastry M, Mayyaa KS, Bandyopadhyay K (1997) pH dependent changes in the optical properties of carboxylic acid derivatized silver colloidal particles. Colloids Surf A Phy Che Eng Aspects 127:221-228

31. White B, Banerjee S, O Brien S, Turro NJ, Herman IP (2007) Zeta-potential measurements of surfactant-wrapped individual single-walled carbon nanotubes. J Phy Chem C 111:13684-13690

32. Baker C, Pradhan A, Pakstis L, Pochan DJ, Shah SI (2005) Synthesis and antibacterial properties of silver nanoparticles. J Nanosci Nanotech 5:244-249

33. Ahmad N, Sharma S, Rai R (2012) Rapid green synthesis of silver and gold nanoparticles using peels of Punica granatum. Int J Nanopar 5:185-195

34. Phanjom P, Zoremi E, Mazumder J, Saha M, Baruah SB (2012) Green synthesis of silver nanoparticles using leaf extract of Myrica esculenta. Int J NanoSci Nanotechnol 3:73-79

35. Kaviya S, Santhanalakshmi J, Viswanathan B, Muthumar J, Srinivasan K (2011) Biosynthesis of silver nanoparticles using Citrus sinensis peel extract and its antibacterial activity. Spectrochim Acta Part A Mol Biomol Spectrosc 79:594-598

36. Rathod V, Banu A, Ranganath E (2012) Biosynthesis of highly stabilized silver nanoparticles by Rhizopus stolonifer and their anti-fungal efficacy. Int J Cur Biomed Phar Res 2:241-245

37. Choi Deng KK, Kim NJ, Ross L, Surampalli RY, Hu Z (2008) The inhibitory effects of silver nanoparticles, silver ions and silver chloride colloids on microbial growth. Water Res 42:3066-3074

38. Brett DW (2006) A discussion of silver as an antimicrobial agent: alleviating the confusion. Ostomy Wound Manag 52:34-41

39. Powers CM, Badireddy AR, Ryde IT, Seidler FJ, Slotkin TA (2011) Silver nanoparticles compromise neurodevelopment in PC12 cells: critical contributions of silver ion, particle size, coating and composition. Environ Health Perspect 119:37-44 
40. Xia T, Kovochich M, Liong M, Mädler L, Gilbert B, Shi H et al (2008) Comparison of the mechanism of toxicity of zinc oxide and cerium oxide nanoparticles based on dissolution and oxidative stress properties. ACS Nano 2:2121-2134

41. Yang H, Liu C, Yang D, Zhang H, Xi Z (2009) Comparative study of cytotoxicity, oxidative stress and genotoxicity induced by four typical nanomaterials: the role of particle size, shape and composition. J Appl Toxicol 29:69-78
42. Franklin NM, Rogers NJ, Apte SC, Batley GE, Gadd GE, Casey PS (2007) Comparative toxicity of nanoparticulate $\mathrm{ZnO}$, bulk $\mathrm{ZnO}$, and $\mathrm{ZnCl}_{2}$ to a fresh water microalga (Pseudokirchneriella subcapitata): the importance of particle solubility. Environ Sci Technol 41:8484-8490

\section{Publish with ChemistryCentral and every scientist can read your work free of charge}

"Open access provides opportunities to our colleagues in other parts of the globe, by allowing anyone to view the content free of charge."

W. Jeffery Hurst, The Hershey Company.

- available free of charge to the entire scientific community

- peer reviewed and published immediately upon acceptance

- cited in PubMed and archived on PubMed Central

- yours - you keep the copyright

Submit your manuscript here:

http://www.chemistrycentral.com/manuscript/

Chemistry Centra 